\title{
Finite element modeling of the influence of residual weld stresses on buckling
}

\author{
A. Outtier \& H. De Backer \\ Ghent University, Ghent, Belgium
}

\begin{abstract}
One of the determining factors in the design of steel-tied arch bridges is the outof-plane buckling behavior. While considerable research, focusing on the determination of the geometrical imperfections, using non-destructive testing as well as analytical calculation methods, is available, the influence of residual welding stresses has not been studied in depth. It is assumed that these stresses would have only limited influence on buckling. Still, this paper claims the residual stresses, which are present in the arches, can be of limited importance, since they do influence the out-of-plane shape of the arch. Firstly, a fundamental approach is followed by developing a three-dimensional finite element model of the influence of the welding parameters and weld sequence. In addition, the resulting residual welding stresses are used for an elastic-plastic calculation of an entire arch. This allows for calculating the buckling behavior of arches as realistically as possible.
\end{abstract}

\section{INTRODUCTION}

The occurrence of thermal residual stresses, introduced in structural shapes by the manufacturing process has a considerable effect on corrosion, brittle fracture and especially on the buckling strength of steel members for most practical column lengths. Residual stresses due to the welding process are discussed in this paper, as well as methods of assessing the typical magnitudes of these stresses. Residual stresses may be remedied by a suitable heat-treatment but in most cases this is impractical and extremely expensive. This is especially true for construction parts of the sizes used for bridge engineering. Mechanical processes such as cold-straightening however, can often be used to alleviate the detrimental effect of residual stresses for specific applications.

Residual, or locked-in, thermal stresses appear in welded, structural components after welding operations. These stresses arise from the non-uniform temperature distribution during the welding process. During the welding of two steel plates, for example, the inner part of the crosssection cools at a slower rate than the outer boundary of the cross-section, so a temperature gradient exists through the steel plates of the cross-section. The contraction of the cooler material is resisted in the hotter regions where a plastic flow takes place in compression, at a low value of yield stress which can be associated with the higher temperatures of the cross-section. The cooler material will thus extend when compared to the hotter core and this latter region will contract during the cooling to ambient temperature after the welding operation, so a reversal in the stresses will take place. The material which cools first is now in residual compression, while the region which cools last is in residual tension. These longitudinal residual stresses must result in a system of forces in the cross-section, which is in internal equilibrium.

Residual stresses have a significant effect on brittle fracture, fatigue, stress corrosion and the buckling strength of structural steel sections. In the ECCS column curves, (European Convention for Constructional Steelwork (ECCS) (1976) and EN 1993-1-1 (2005)) only their particular effect on the buckling strength has been studied. 
A combination of applied and residual stresses will induce inelastic behavior in a member cross-section at levels of applied stress which are lower than yield stress. Since plastic material, which has not completed its elastic unloading cycle can make no contribution to resist bending of the structural member, a fundamental knowledge of the effective cross-section stiffness under load is essential for further buckling calculations. When buckling is not a consideration, the fully plastic load carrying capacity is not impaired, but deformations will be greater than in a corresponding stress-free member.

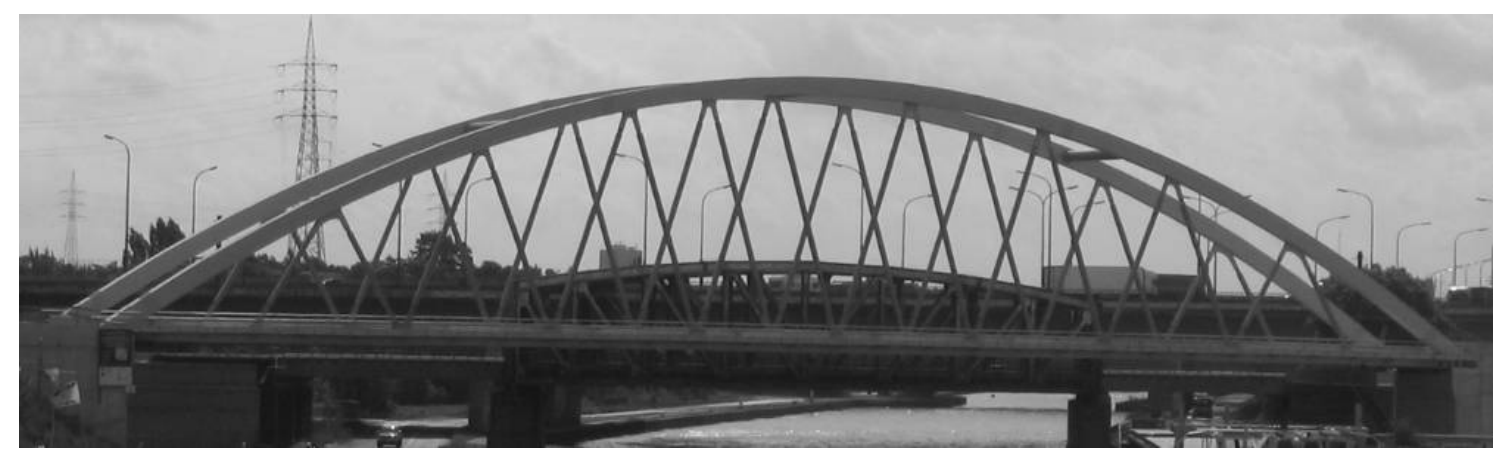

Figure 1. The Albert Canal Bridge and the dimensions of the arch cross-section.

\section{DESCRIPTION OF THE OVERALL FINITE ELEMENT MODEL}

The cross-section of the arch from a recently build bridge in Belgium, the Albert Canal Bridge near the city of Antwerp was the basis of the research into the influence of the residual stresses to the out-of-plane buckling behavior. The box-section of the arch consists of four separate steel plates, welded together with fillet welds. A general overview of the bridge can be seen in Figure 1.

A finite element model of that arch box-section was built out of 3D volume elements in the finite element software packet Samcef (2002). Due to the complexity of the problem and due to the required computer time, the cross-section was coarsely modeled (element sizes in the order of $5 \mathrm{~cm}$ ) and only in the corners, where the plates are welded together, is the size of the elements chosen smaller than in the other parts of the steel plates (element size in the order of 1-2 mm). Those 3D volume elements make it possible to calculate the thermal gradient through the thickness of the steel plates. This temperature gradient will result in a variation of the residual stress due to welding over the cross-section of the arch.

The finite element model of the welding process contains all the different stages of the welding process of the cross-section. The welding of the box section starts with positioning one of the web plates on two simple supports. The lower flange is then positioned vertically near the edge of the web plate, its movements constricted horizontally by a clamp. The two steel plates are welded together by means of two fillet welds, one on each side. The whole work-piece is then turned upside down and positioned on the second web plate, which was also placed on two simple supports. The already welded web plate is at the same time supported by a steel rod. The second web plate is also welded to the lower flange using two identical, one-pass fillet welds. Afterwards, the steel rod, supporting the web plate, is moved to the center of the box section and the top flange is positioned. The top flange is then connected to each web plate using a single pass fillet weld at the outside of the box-section and fillet weld using three independent weld passes at the inside of the box section. The most important steps of the weld process described above are illustrated in Figure 2 from a mechanical perspective, while the order of the different weld passes is given in Figure 3. The used welding process is Flux Cored Arc Welding (FCAW) which produces the necessary heat by creating an electrical arc between the electrode, a continuously supplied welding wire and the steel plates. This method allows for high weld speeds and good weld penetration.

One of the most difficult problems in the finite element modeling of welding operations is modeling the connection between separate plates after the passage of the welding torch. In the 
beginning of the analysis, all of the plates of the arch section are not connected to each other, so the temperatures in two different plates will differ from each other. Once, the temperature exceeds a certain temperature level, the melting temperature, the plates are connected and heat flux is allowed between the two connected plates as if it was one continuous material. Lindgren (2001a) and Runnemalm et al. (1999) describe two different possibilities to simulate this connection: "silent elements" and "inactive elements".
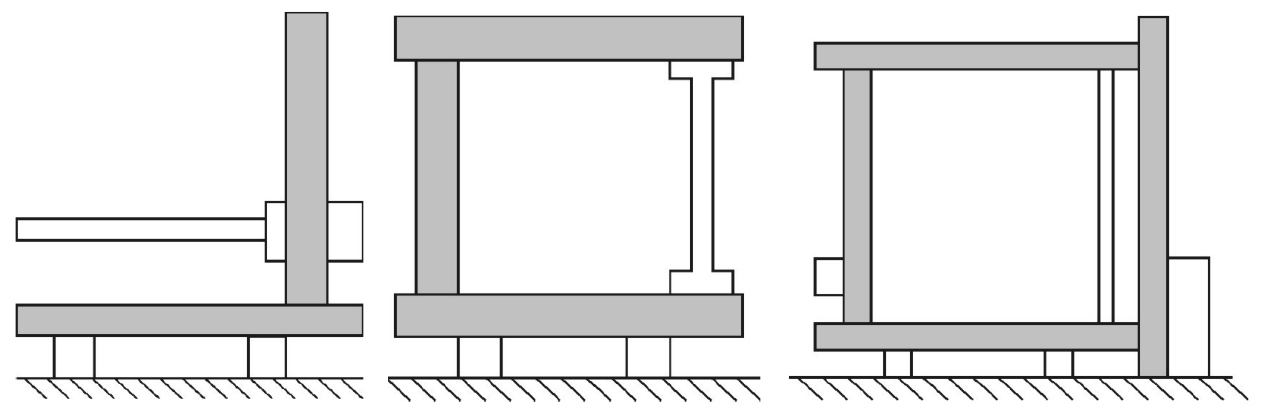

Figure 2. Steps and boundary conditions during the welding of the box girder.

Figure 3. Order of the weld passes during the welding procedure.

A special connection-element, dependent on the temperature, was developed in the finite element code based on the theory of "inactive elements". This theory was chosen since the amount of added materials is rather limited. In addition, the ends of the four plates forming the box section were not beveled, further justifying the use of "inactive elements" over "passive elements". The connection- element is only active, when a certain temperature is achieved. Once the elements are activated, they stay active for the rest of the analysis. Due to the connection element, the temperature on both sides of the weld will become the same once the connecting element is activated. The calculated temperatures are then used in the mechanical analysis, where once again, as soon as the connection element is activated, the distance between the steel plates will be "frozen" to the distance obtained at the last step before welding, so a rigid connection emerges representing the physical welding of both plates.

A thermal analysis of the model was run in the finite element program, incorporating all of the separate stages of the welding process. Afterwards the resulting temperatures were used as an input for a mechanical analysis, which calculated the residual stresses during all those stages, based on the varying boundary conditions.

\section{THERMAL ANALYSIS}

The heat input of a welding torch around a welding pool has a double-ellipsoid shape, as was mentioned in Gery et al. (2005), Goldak et al. (1984) and De Strycker (2004). The heat source distribution, as shown in Figure 4 combines two different ellipses, i.e. one in the front quadrant of the heat source and the other in the rear quadrant. The power densities of the double-ellipsoid heat source $q_{f}(x, y, z)$ and $q_{r}(x, y, z)$ describing the three-dimensional heat flux distributions inside the front and rear quadrant of the heat source can be expressed by Eq. (1) and Eq. (2). In these equations, $Q=U \cdot I \cdot \eta$ equals the energy input rate which is determined by the welding current $I$, the operating voltage $U$ of the welding unit and the efficiency $\eta$. The weld parameters used at the Albert Canal Bridge are summarized in Table 1. The constants $a, b, c_{f}$ and $c_{r}$, as shown in Figure 4, are heat source parameters that define the size and shape of the ellipses and therefore the heat source distribution. Here, the parameters $a, b, c_{f}$ and $c_{r}$ were determined according to the method explained by Palani and Murugan (2006). All of these parameters need to be determined so that the connection between both ellipsoids remains continuous and are summarized in Table 2. 


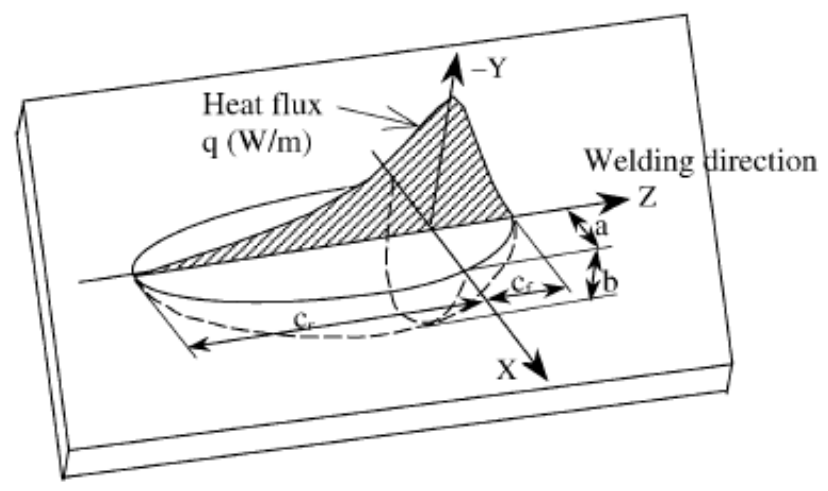

Figure 4. Goldak’s double ellipsoid heat source model (Goldak et al. (1984)).

Table 1. Weld parameters of the arch of the Albert Canal Bridge.

\begin{tabular}{lccc}
\hline Weld parameter & Units & Weld type A & Weld type B \\
\hline Welding current & $\mathrm{A}$ & 585 & 210 \\
Operating voltage & $\mathrm{V}$ & 29 & 27.5 \\
Weld speed & $\mathrm{mm} / \mathrm{min}$. & 47.5 & 25 \\
Distance between electrode and steel plate & $\mathrm{mm}$ & 17.5 & 17.5 \\
Used at weld passes & $/$ & $1,2,3,4,5$ and 9 & $6,7,8,10,11$ and 12 \\
(see Figure 3) & & & 0.9 \\
Efficiency $\eta$ & $\mathrm{mm}$ & 12.5 & 10.45 \\
$a$ & $\mathrm{~mm}$ & 0.95 & 1.06 \\
$b$ & $\mathrm{~mm}$ & 6.25 & 5.22 \\
$c_{f}$ & $\mathrm{~mm}$ & 25 & 20.89 \\
$c_{r}$ & $/$ & 0.4 & 0.4 \\
$f_{f}$ & $/$ & 1.6 & 1.6 \\
$f_{r}$ & $\mathrm{~W}$ & 15268.5 & 5197.5 \\
Heat Input & & & \\
\hline
\end{tabular}

$$
\begin{aligned}
& q_{f}(x, y, z)=\frac{6 \cdot \sqrt{3} \cdot f_{f} \cdot Q}{a \cdot b \cdot c_{f} \cdot \pi \cdot \sqrt{\pi}} \cdot e^{-3 \cdot \frac{x^{2}}{a^{2}}} \cdot e^{-3 \cdot \frac{y^{2}}{b^{2}}} \cdot e^{-3 \cdot \frac{z^{2}}{c^{2}}} \\
& q_{r}(x, y, z)=\frac{6 \cdot \sqrt{3} \cdot f_{r} \cdot Q}{a \cdot b \cdot c_{r} \cdot \pi \cdot \sqrt{\pi}} \cdot e^{-3 \cdot \frac{x^{2}}{a^{2}}} \cdot e^{-3 \cdot \frac{y^{2}}{b^{2}}} \cdot e^{-3 \cdot \frac{z^{2}}{c r^{2}}}
\end{aligned}
$$

The geometrical parameters $f_{f}$ and $f_{r}$ respectively, are the fractional factors of the heat deposited in the front and rear quadrant, which can be determined by

$$
f_{f}+f_{r}=2
$$

As can be seen from Eq. (1) and Eq. (2), Goldak's heat source model is defined as a function of position and time together with a number of parameters, which affect the heat flux magnitude and distribution (Goldak et al. (1984)). Some experimental work has been carried out to investigate the relationships between the heat source definition and the weld pool shapes (Wahab and Painter (1977)). It has been shown that the welding process parameters, such as the welding current and speed, have an important influence on the length of the weld pool.

In order to simulate the movement of the welding torch with the specified speed, the calculated volumetric heat flux density needs to be assigned to specific elements of the finite element model around the welding area in the finite element model at the correct time. This can be realized by making the heat flux distribution dependent of the time instead of the geometric coordinates in the weld direction. By doing this, the formulation of the amplitude curves demand a lot of 
computer capacity, for every time increment the heat flux Eq. (1) and Eq. (2) must be integrated. For every finite element, the amplitude curves give the distribution of the introduced heat as a function of the time, in steps equal to one increment, and are thus the thermal loading in the finite element model.

An alternative method, is to integrate equations (1) and (2) over the welding depth $b$ and the welding width $a$. This results in:

$$
\begin{aligned}
& q_{i, j}(z)=\mathrm{A}_{i, j} \cdot e^{-0.0768 \cdot z^{2}}, z>0 \\
& q_{i, j}(z)=\mathrm{A}_{i, j} \cdot e^{-0.00480 \cdot z^{2}}, z \leq 0
\end{aligned}
$$

The integration parameters $A_{i, j}$ are determined in a discrete manner, taking the size and distribution of elements at the weld into account. The graph of the applied heat flux is then different for each element in the weld region. A number of these heat flux variations are shown in Figure 5, including the maximal value. The graph of the heat flux, see Figure 5, is then divided into strips with a length $\Delta z=v \cdot \Delta t$, with $v$ the welding speed and $\Delta t \approx N / v$ with $N$ a natural number.

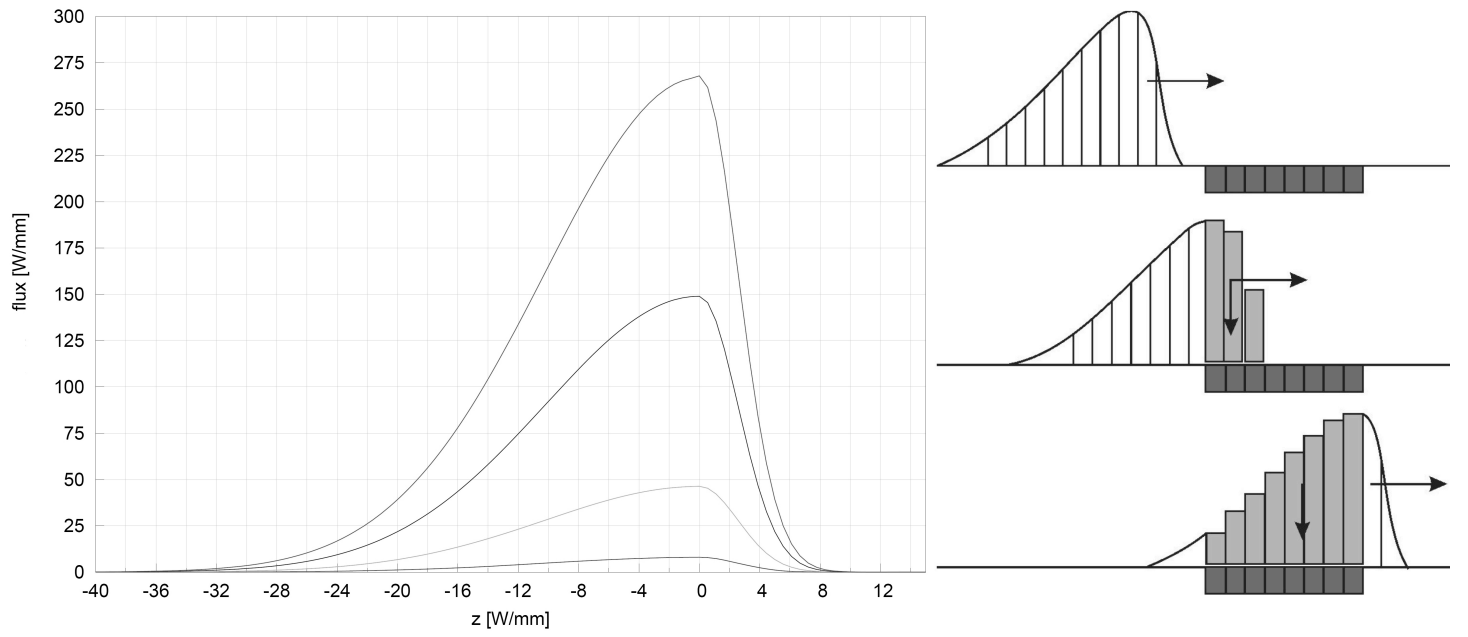

Figure 5. The heat flux curves (left) and illustration of the discretization process (right).

In all of these subintervals, the heat flux is estimated by its mean value in that subinterval and the intervals length. The heat flux for each individual subinterval is then:

$$
\frac{q_{i}+q_{i+1}}{2} \cdot \Delta z
$$

The calculation of this problem in the finite element program Samcef is also performed by time steps. The size of the elements in the welding direction is chosen based on the fact, that the welding torch covers a distance equal to one element during a single time step. In the beginning, on time step $t_{0}$, there is no heat flux acting on the steel plates. On the first time step $t_{1}$, the welding torch has moved over a distance $v \cdot t_{1}=n_{1} \cdot \Delta t$. So, the summation of the first $n_{1}$ strips of the heat flux graph must be introduced at the first element. At the second time step, the torch has moved over a distance $v \cdot t_{2}=n_{2} \cdot \Delta t$. Then, the heat flux acting on the model equals the summation of the first $n_{2}$ strips. The same argumentation holds true until the covered distance of the torch equals the length of the heat flux graph. Then the whole area under the curve must be placed on the model. When the covered distance of the welding torch passes the length of the finite element model, only the summation of the last strips must be taken into account.

Like this, the welding torch, which moves continuous in reality, is introduced into the finite element model in a discontinuous manner.

After the welding process, the steel plates are mainly cooled down by convective cooling and heat radiation with the environment. Radiant heat between the different steel plates can be de- 
scribed by:

$$
q=\varepsilon \cdot \sigma \cdot\left(\left(\theta-\theta_{z}\right)^{4}-\left(\theta_{0}-\theta_{z}\right)^{4}\right)
$$

Herein $q$ is the heat flux per area unit, $\varepsilon$ the emissivity, $\sigma$ the constant of Stephan Boltzmann, $\theta$ the temperature on the surface of the steel plates, $\theta_{z}$ the absolute zero-temperature and $\theta_{0}$ the surrounding temperature. The emissivity is a number between 0 and 1 , without dimension and is influenced by the state and the color of the steel surface. For steel, a wide range of values for the emissivity is given in De Strycker (2004), varying between 0.08 and 0.97 . But, a study of the influence of the emissivity on the resulting residual stresses in the welded section (De Strycker (2004)) has shown that the emissivity has almost no influence on the residual stresses. In this research, a value of 0.90 is used.

Although cooling down by convection is small in comparison to radiation, the effect of convection is not neglected in the finite element model. Heat transfer by convection between the exterior surfaces of the finite element model and the surrounding air, can be modeled as a boundary condition, the thermal flux of which is determined by Newton's law:

$$
q_{c}=h_{c} \cdot \sigma \cdot\left(\theta-\theta_{0}\right)
$$

where $h_{c}$ equals the thermal exchange coefficient for convection and $A$ the surface area. The value of the coefficient $h_{c}$ is dependent on temperature, nature of the exchange medium and air velocity v. Some values have been proposed in Recknagel (1995) for this coefficient:

$$
h_{c}=\left\{\begin{array}{cc}
4.2 v_{l}+6.2 & v_{l}<5 \mathrm{~m} / \mathrm{s} \\
15 v_{l}^{0.78} & v_{l} \geq 5 \mathrm{~m} / \mathrm{s}
\end{array}\right.
$$

The simulation of the welding process needs the input of the variation of the thermal properties of the steel material with the temperature. The variation of these properties can be found in EN 1993-1-2 (1999) which delivers comparable values as Lindgren (2001b), Brown and Song (1992) and Ferwin and Scott (1999).

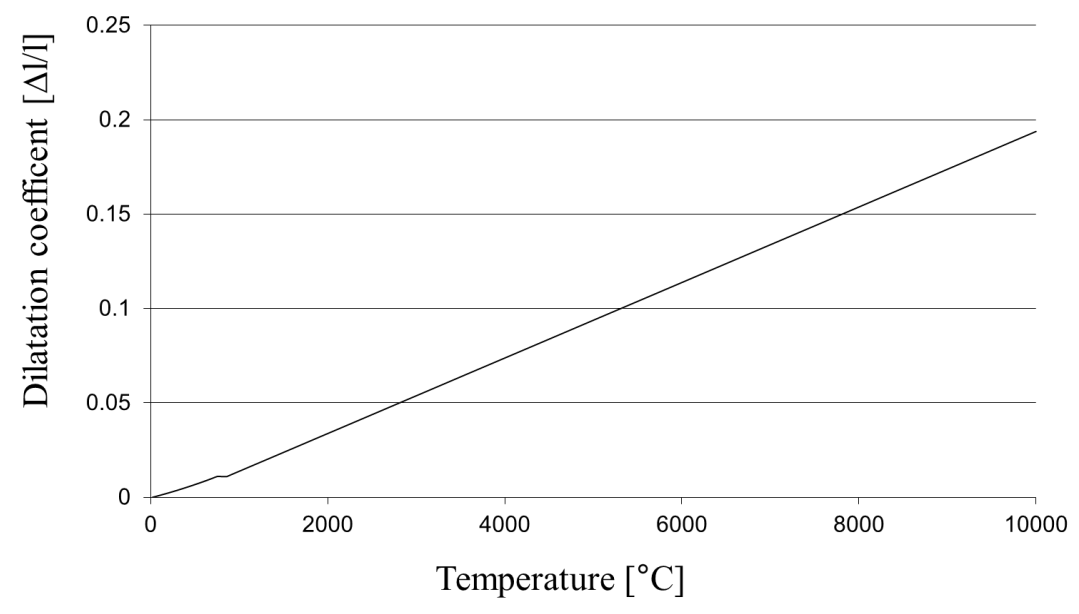

Figure 6. The dilatation coefficient as a function of the temperature.

The variation of the dilatation coefficient as a function of the temperature is shown in Figure 6, using the formulas as described in the Eurocode, EN 1993-1-2 (1999). This variation of the dilatation is introduced in the finite element model as being purely reversible, although in literature, an irreversible variation with a thin hysteresis curve is sometimes given. The cooling path would then be dependent of the maximal achieved temperature. 


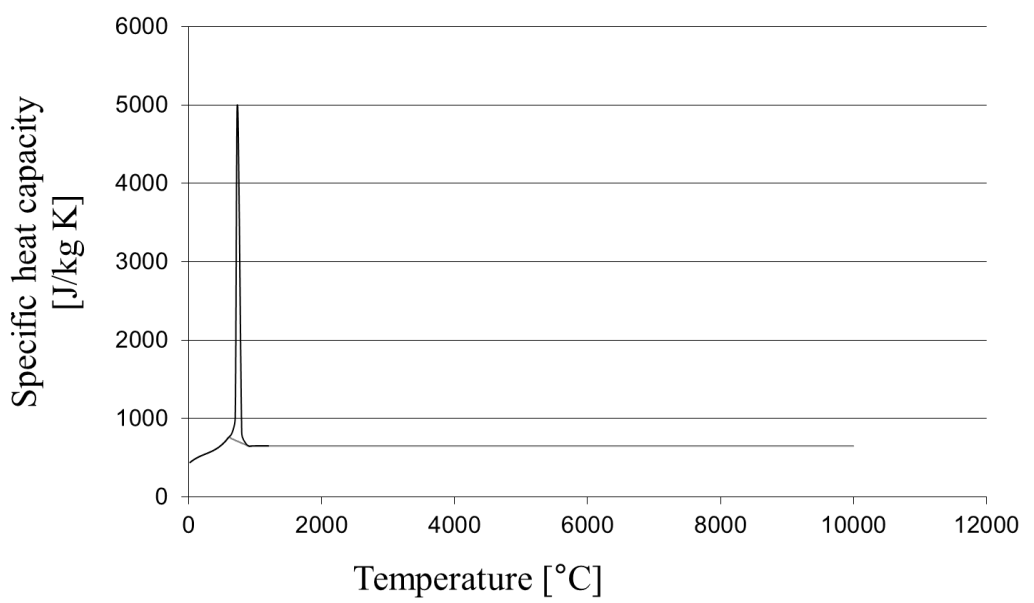

Figure 7 . The specific heat capacity as a function of the temperature.

Figure 7 shows the variation of the specific heat capacity as a function of the temperature, as it is defined in the Eurocode, EN 1993-1-2 (1999). One problem arises, when this temperature variation is implemented in the finite element code. As the temperatures nears the peak in the heat capacity variability, between $600^{\circ} \mathrm{C}$ and $800^{\circ} \mathrm{C}$, a problem will arise during one calculation step, because the finite element program will interpret this as if the specific heat capacity becomes infinitely large. This will terminate the calculation. This peak in the specific heat curve corresponds with the latent heat because of the crystallographic phase shift which occurs at that temperature. Taking into account that the influence of the specific heat capacity on the residual stresses is limited, a simplification of the curve, near this peak is carried out, as can be seen in Figure 7.

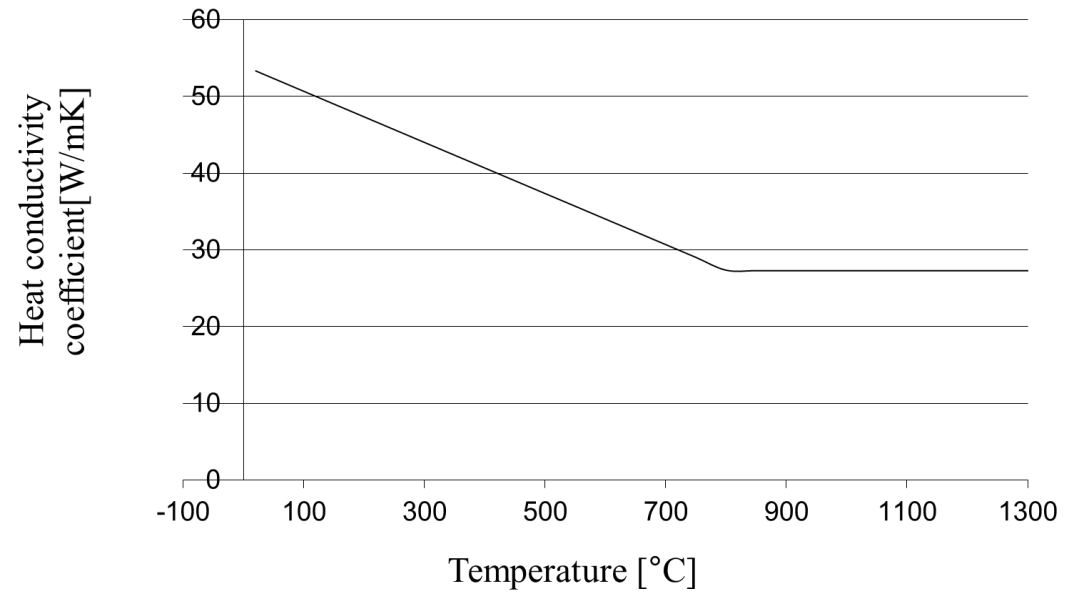

Figure 8 . The heat conductivity coefficient as a function of the temperature.

The heat conductivity coefficient, as it is shown in Figure 8, has the largest influence on the temperature variation in the steel section of all of the previously discussed heat input parameters. The larger the heat conductivity coefficient becomes, the larger the heat flux will be, diverting the heat flow away from the welding zone and thus resulting in a much smaller maximal temperature in the steel and also a smaller temperature gradient. Since EN 1993-1-2 (1999) only defines the conductivity for temperatures up to $1200^{\circ} \mathrm{C}$, the curve has been extended, based on the values of Ferwin and Scott (1999) to include higher temperatures, which is necessary for welding.

All other parameters, such as emissivity, absorptivity, etc. can be found in EN 1993-1-2 
(1999) in temperature-dependent form. They are not discussed in detail because their influence or variation is in most cases quite small.

\section{MECHANICAL ANALYSIS}

The second part of the research consists of a mechanical analysis in which the previously derived temperature distribution is used as a thermal load, resulting in the determination of the residual weld stresses. During this second part, all mechanical boundary conditions are varied identical to the actual handling of the box section during the welding, using several clamps, struts, etc. These boundary conditions restrict the expansion of the steel during the heating and differential cooling of the material. Normally, the boundary conditions are introduced in the finite element program as full or partial fixations, which cannot change in time. But, since the boundary conditions change during the welding process, they were introduced as prescribed time-dependent displacements equaling zero when fixed. On overview of the most important boundary conditions can be found in Figure 2 and paragraph 2.

And at last, the material model was changed, for the mechanical analysis: the Young's modulus, the shear modulus and the yield criteria needed to be defined in temperature dependent form. The Young's modulus is dependent of temperature. The definition of those parameters was once again done based on the Eurocode (EN 1993-1-2 (1999) and Outtier et al. (2006)). The yield strength decreases with increasing temperature. For steel with a yield strength of $235 \mathrm{MPa}$ at $20^{\circ} \mathrm{C}$, the yield strength decreases to a value of $9.4 \mathrm{MPa}$ at a temperature of $1000^{\circ} \mathrm{C}$. Theoretically, the yield strength must be zero when the steel flows. But then, the movement of the elements in the finite element model would also become equal to infinity, so that the calculation would be unstable and stop prematurely. Yield strength is thus never reduced to 0, but to relatively very small value. Since the variation of the modulus of Poisson with temperature has a much less important influence on this calculation, it wasn't modeled (De Strycker (2004) as a variable, but with a constant value of 0.3 .
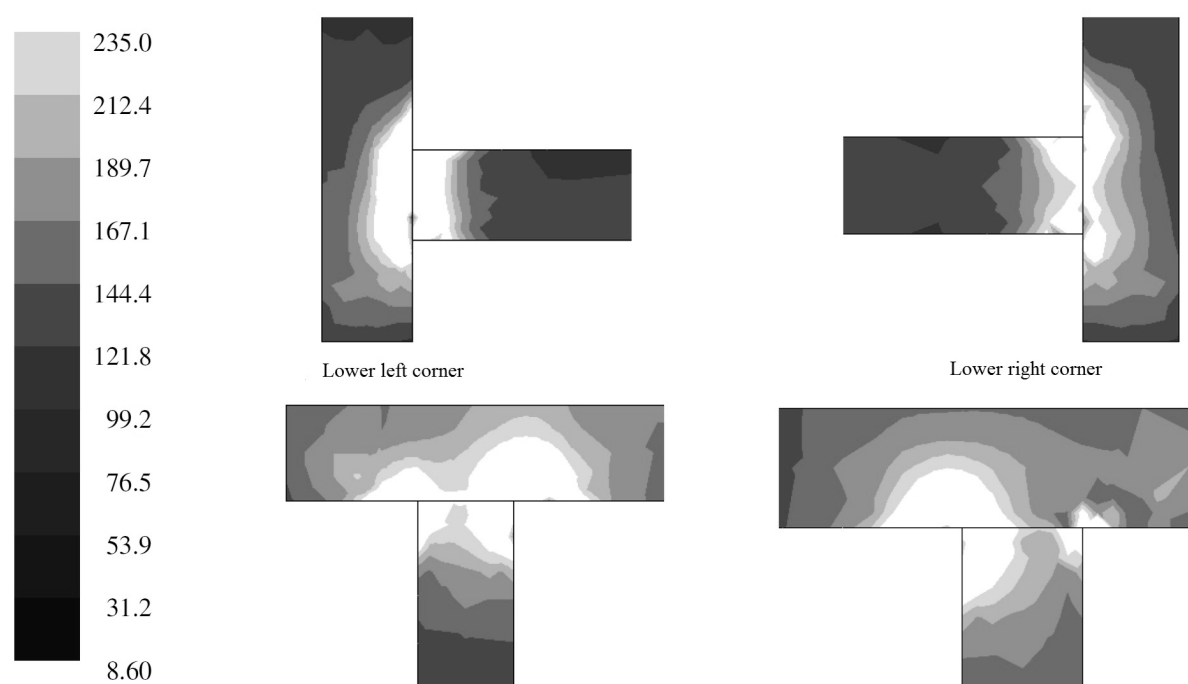

Lower left corner

Lower right corner
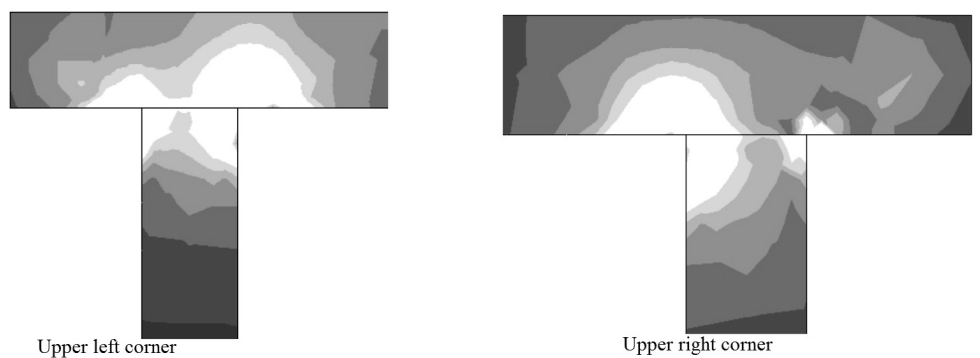

Figure 9. Residual stresses in the corners of the box section (Stresses in MPa).

\section{RESIDUAL WELD STRESSES BASED ON FINITE ELEMENT RESULTS}

The overall conclusion of both calculation steps is that important residual tensile stresses will arise close to all welds, while small compressive stresses occur in the rest of the cross-section, as can be seen in Figure 9 which displays the residual stresses in the corner node of the arch box 
section, based on the Von Mises criterion. This criterion is chosen because it offers a conveniently clear stress distribution, though it must be stressed that tensile and compressive stresses will occur (see also Figure 11 and Figure 12).

Furthermore, it seems that the heat-influenced region will be considerably bigger, if multiple weld steps are used, thus resulting in a larger area with important residual stresses as can be seen by comparing the upper and lower corners of the arch cross-section, which were subjected to 2 and 4 weld passes respectively. In addition, the distribution of the weld stresses over the crosssection is found to be slightly asymmetrical due to the asymmetrical order in which all weld passes are executed and the asymmetry of the boundary conditions during welding, as shown in Figure 9. It is quite clear that the influence of the residual weld stresses is limited to a very small region and does not really influence the stress field at a distance of 1,5 times the plate thickness from the corners of the arch box section.

Completely in accordance to what was to be expected, the residual stresses have the most significant values in the corners of the cross-section, as can be seen very clearly in Figure 9. In the midpoints of the steel plates, the residual stresses remain very low and are almost non-existent. On the other hand, it seems as if the residual stresses in the corners of the cross-section reach considerable values. Still, the distribution of the residual stresses seems to be pretty symmetrical over the entire cross-section. The stress field can easily be represented by a simplified extrapolation wherein very large tensile residual stresses exist in the four corners of the arch box sections, which are in equilibrium with smaller residual stresses in compression, which exist in the rest of the arch box section. This simplification can then be imposed on detailed finite element models (Outtier et al. (2006)) arch section, to incorporate the influence of residual stresses in buckling analysis, as has always been the guideline of the ECCS (European convention for Constructional Steelwork (1976)).

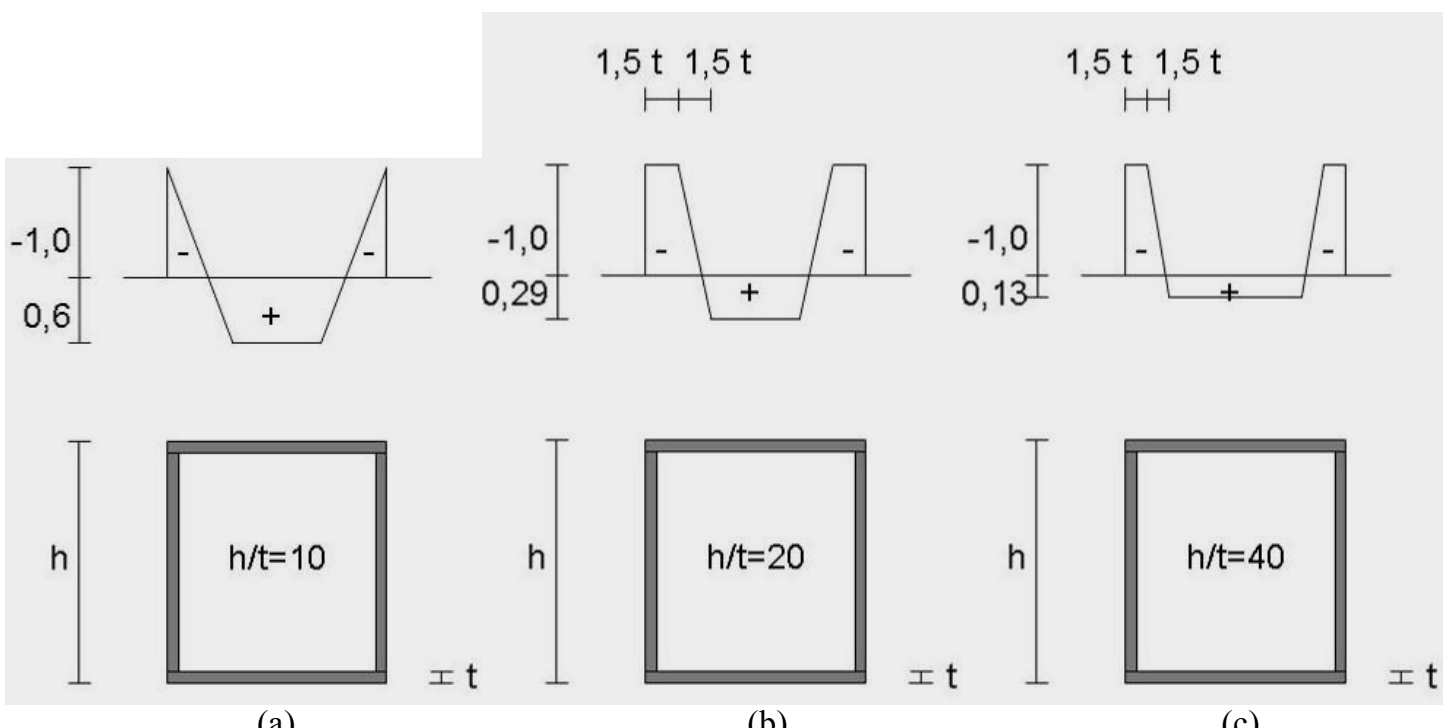

Figure 10. Residual stresses in the box section, relative to yield stress.

At present, the only distribution of residual weld stresses that is available in literature for box cross-sections is the one that is given in European convention for Constructional Steelwork (1976). This stress distribution is summarized in parts (a), (b) and (c) of Figure 10 and is based on experimental results as well as analytical deductions derived from other residual stress distributions. The most obvious disadvantage of the available stress distributions is that they are derived for essentially more compact sections as those found in arch bridges.

The values in Figure 10 (a) are based on experimental results by Mass and Massonet (1966) and Tebedge and Tall (1973) for residual weld stresses in box sections having a height-tothickness ratio of about 10 and overall dimensions smaller than $500 \mathrm{~mm}$. The diagrams in figure 10 (b) and (c) are also derived from literature and correspond with box sections whereof the ratio between height and plate thickness varies between 20 and 40. In addition, these two stress 
distributions assume that the welds connecting the four plates of the box are relatively light, which needs to be interpreted as the overall dimensions of the box varying between values of 500 and $1000 \mathrm{~mm}$. Since most arch bridges are designed using arch cross-sections having considerably larger dimensions, these theoretical residual stress distributions cannot be used in a safe manner.

Nevertheless, a more generalized symmetrical residual stress distribution can be proposed, which can be used for further calculation, based on the finite element calculation in the present research. However, distinction has to be made between slender (height to width ratio of about 40, Figure 11) and more robust cross-sections (height to width ratio of 15 and lower, Figure 12). The area with high residual stresses will be comparable for both types of box sections. However, the area over which the high tensile stresses decrease is much more important for robust crosssections. This will also result in the compressive stresses, halfway between welds, to be slightly higher in comparison since the overall compression and tension in the cross-section has to be in equilibrium. Comparing these results with the accepted literature values in Figure 10, it is obvious that the area where residual weld stresses would occur is quite similar (compare Figure 11 with Figure 10 (c)). However, area over which the residual stress decrease is proven to be a lot smaller then was generally assumed. A comparison between both is given in Figure 13.

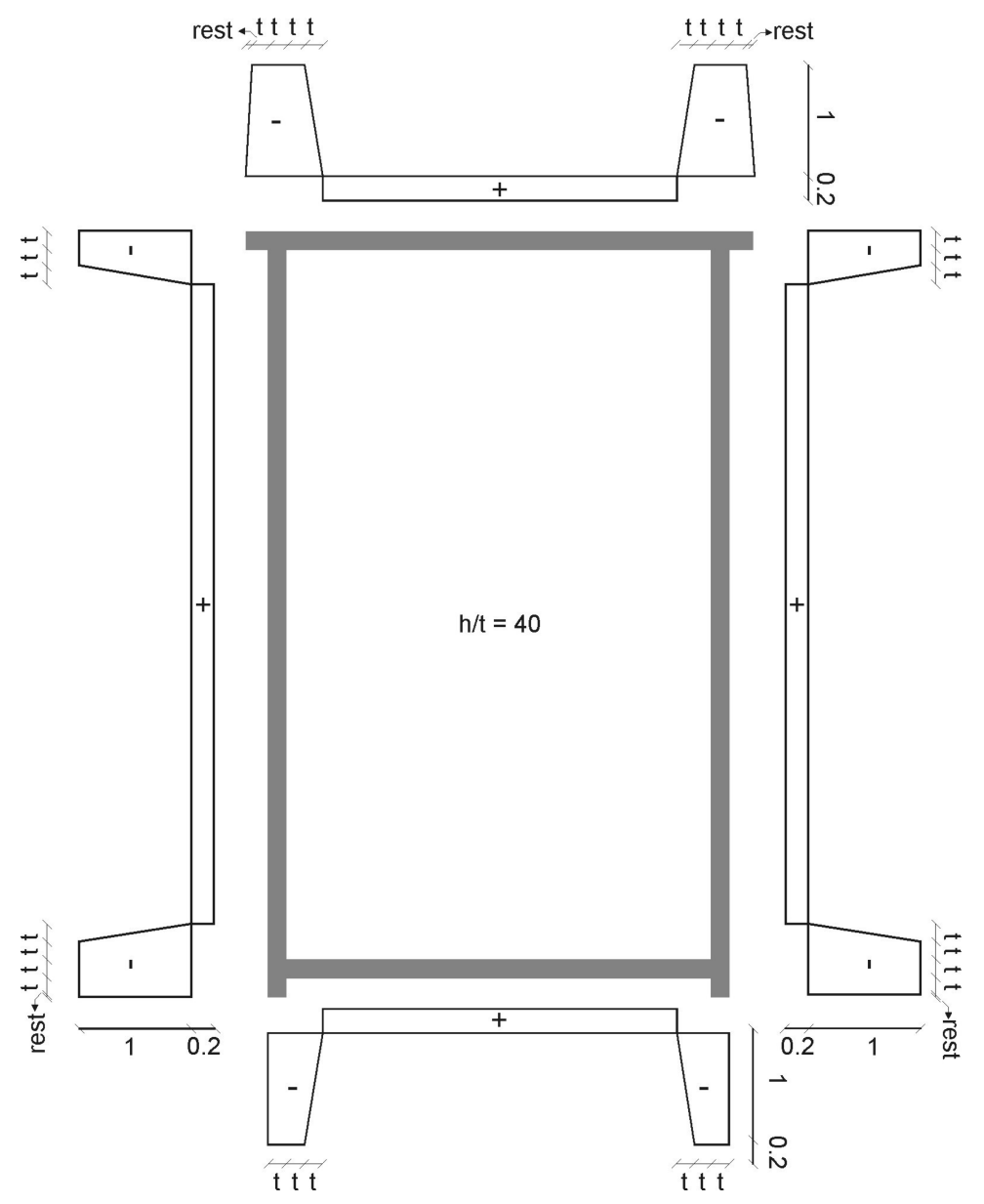

Figure 11. Residual weld stresses in slender box sections, relative to the yield stress.

In a final part of this research project, the influence of this residual weld stress distribution on the buckling behavior of arch bridges will be studied using nonlinear-elastic buckling calculations of highly detailed finite element models of recently built arch bridges. The overall conclusion has to be that a certain influence exists, but that it is quite small due to size of the considered cross-sections. This is discussed in the following paragraph. 


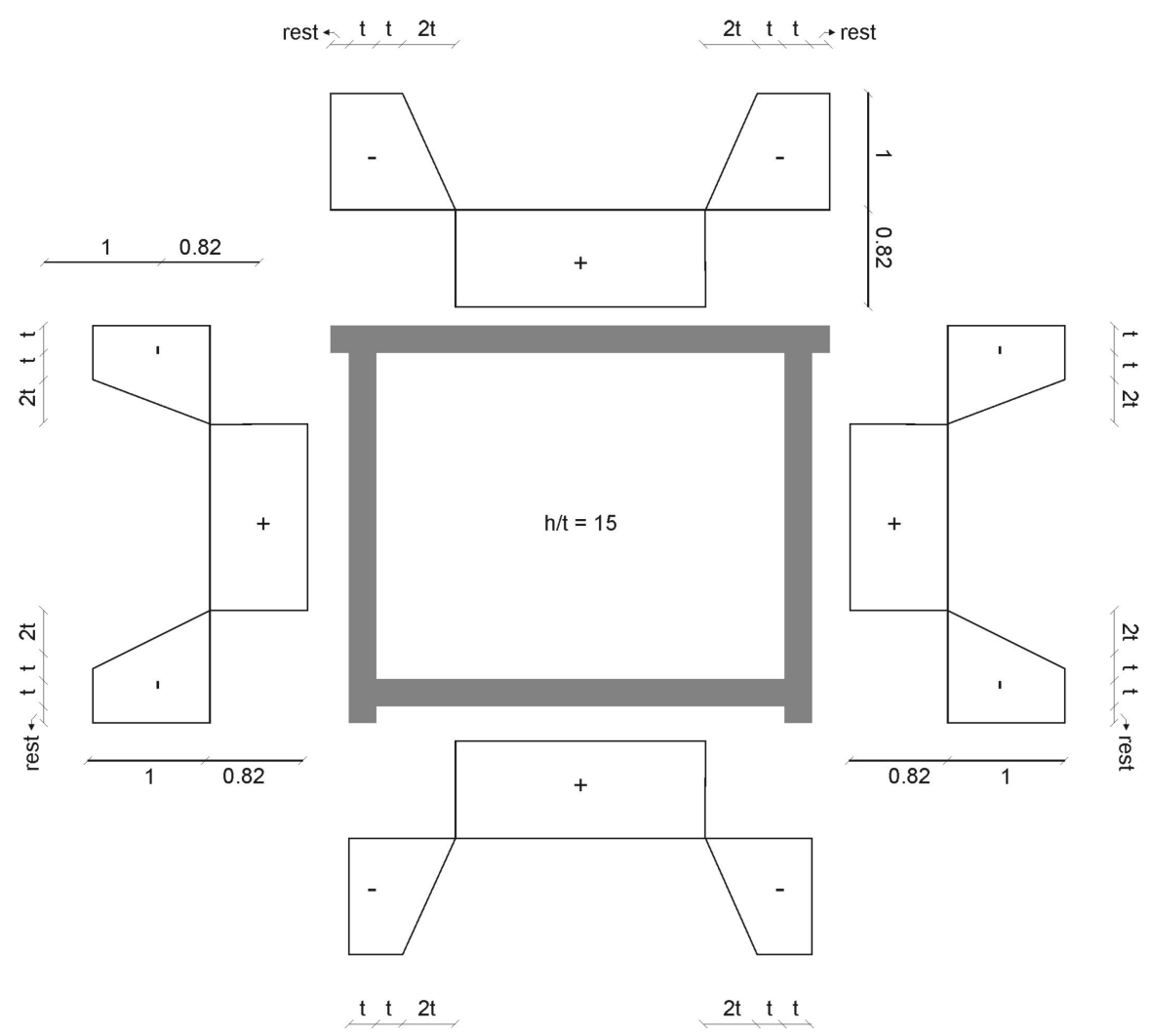

Figure 12. Residual weld stresses in robust box sections, relative to the yield stress.
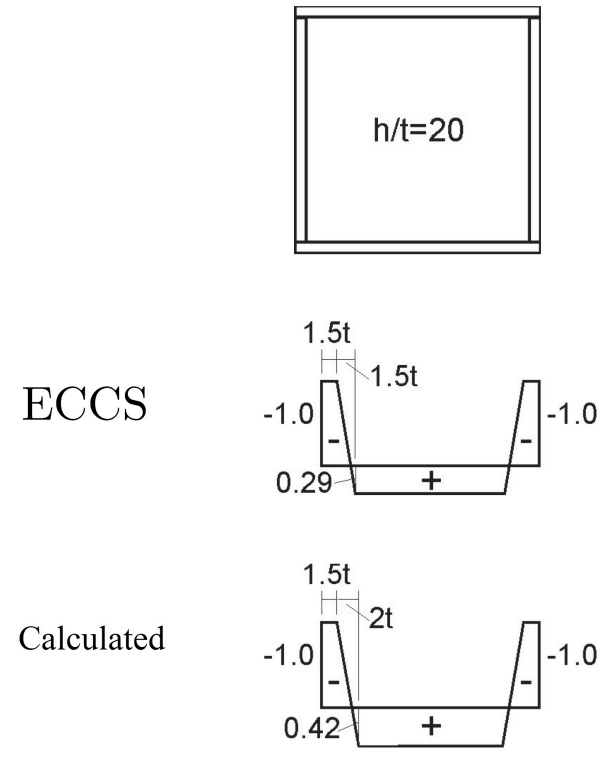
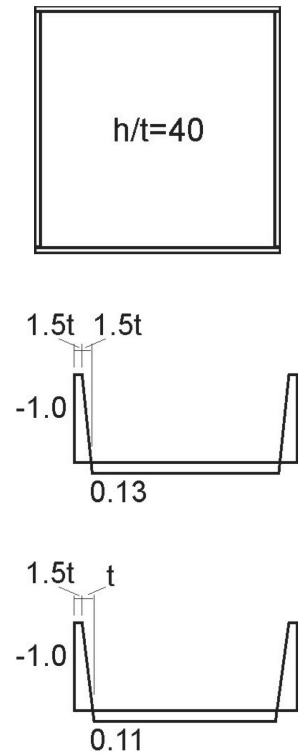

Figure 13. Comparison of the calculated residual weld stresses with values from literature (European convention for Constructional Steelwork (1976)), relative to yield stress. 


\section{INFLUENCE ON THE BUCKLING BEHAVIOR}

The residual stress distribution, as shown in Figure 11, is applicable for the Albert Canal Bridge which was described in paragraph 2 . The entire tied arch is modeled and subject to a buckling calculation in which the overall loading is gradually increased. The results of this calculation are summarized in Figure 14. The upper row of Figure 14 shows the occurring stresses in one of the web plates of the box section at the top of the arch for a model without the influence of weld stresses. The second row, on the other hand, clearly illustrates the influence of the residual stresses.
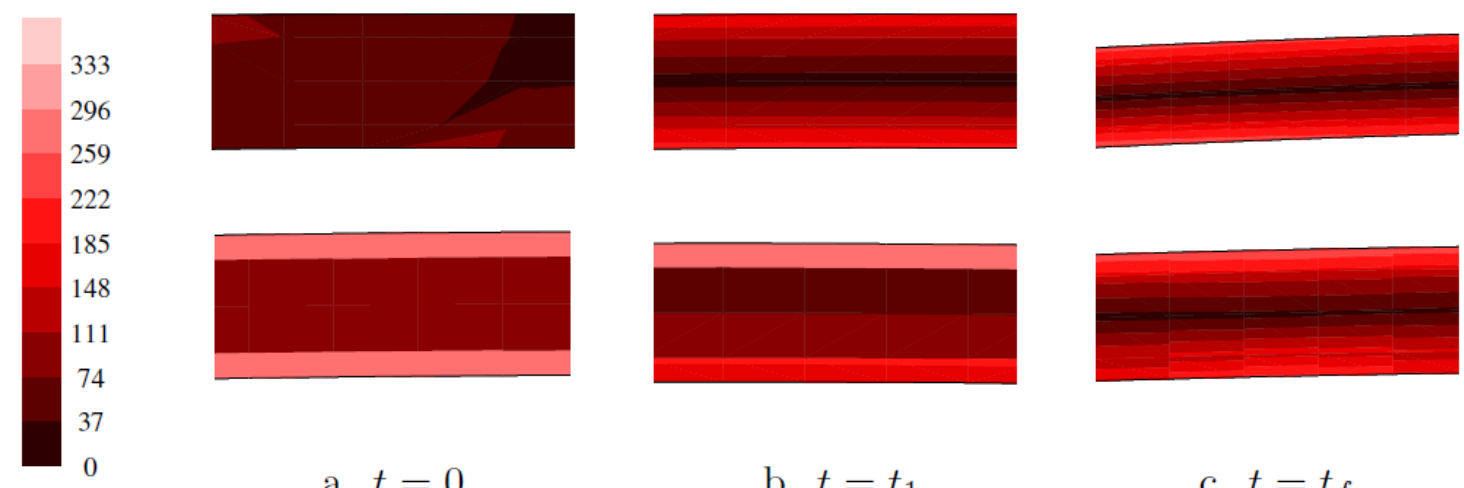
a. $t=0$
b. $t=t_{1}$
c. $t=t_{f}$

Figure 14. Stresses (MPa) in the arch cross-section with increasing loads, with (upper) and without (lower) the influence of residual weld stresses.

The first column in Figure 14 represents the initial condition of the arch bridge before it is loaded by external forces. The difference between both rows is quite obvious. The zones which are influenced by the residual weld stresses are clearly recognizable near the corners of the box section. The next column is then a situation where the bridge is loaded by a normal live load, comparable to the one during load tests. Afterwards, all live loads are gradually increased until buckling occurs, which is shown in the figures of the last column. As the overall stress level rises it is apparent that the influence of the residual stresses on the stress distribution diminishes. At the moment of buckling the influence is almost negligible.

Table 2. Influence of residual weld stresses on the buckling factor of tied-arch bridges and without (lower) the influence of residual weld stresses.

\begin{tabular}{lcccccc}
\hline & \multicolumn{2}{c}{ Bridge geometry } & Arch Cross-section & \multicolumn{2}{c}{ Buckling factor } \\
\cline { 2 - 6 } Bridge & $\begin{array}{c}\text { Lengt } \\
\mathrm{h}\end{array}$ & $\begin{array}{c}\text { Height } \\
{[\mathrm{m}]}\end{array}$ & $\begin{array}{c}\text { Height } \\
{[\mathrm{mm}]}\end{array}$ & $\begin{array}{c}\text { Width } \\
{[\mathrm{mm}]}\end{array}$ & $\begin{array}{c}\text { With- } \\
\text { out weld } \\
\text { stresses }\end{array}$ & $\begin{array}{c}\text { With } \\
\text { weld } \\
\text { stresses }\end{array}$ \\
\hline Albert Canal Bridge & 115.0 & 15.0 & 1332 & 920 & 0.307 & 0.302 \\
IJzerlaan Bridge & 56.0 & 9.2 & 680 & 850 & 0.741 & 0.732 \\
Kapelse Steenweg Bridge & 60.0 & 12.0 & 686 & 850 & 0.570 & 0.566 \\
Prester Bridge & 136.2 & 23.6 & 1500 & 1100 & 0.293 & 0.284 \\
\hline
\end{tabular}

The same conclusion is true for the buckling factors. The normal buckling factor $\chi$, without the influence of residual stresses for the case of the Albert Canal Bridge is 0.307. Similar calculations, but with the influence of residual stresses give a buckling factor of 0.302 . In addition, the difference between the maximal elastic buckling forces in the arch based on an elasto-plastic calculation is limited to less than $1 \%$. Similar results are found when the overall dimensions of the considered tied arch bridge are varied within practical limits for slender as well as for robust cross-sections, as is shown in Table 2.

Even the bridges crossing the IJzerlaan and the Kapelse Steenweg, which have a much more robust cross-section, are only slightly influenced by taking account of the residual weld stresses during buckling calculations. Overall, it can be concluded that the influence of welding operations and the resulting residual weld stresses is mostly negligible on the buckling behavior of 
tied-arch bridges. Only if a situation would arise wherein the welding would result in an actual deformation of the structure, thus creating an additional imperfection, would the influence be of importance. While the residual stresses can initially be quite high, the zone in which they occur will be quite limited due to the size of arch bridge cross-sections. In addition, once the overall stresses rise because of an increasing live load, the stress field in an arch cross-section will become more uniform, thus reducing the actual impact of the residual weld stresses.

In the ECCS column curves, (European Convention for Constructional Steelwork (1976)), a geometric imperfection with maximal amplitude of 1/1000th of the arch span is postulated. The influence of residual weld stresses is not implicitly part of this design method, which seems to be a better design assumption than the methods proposed in Annex D of EN 1993-2 (2005).

\section{CONCLUSIONS}

The research in this paper takes a first step in the determination of the influence of residual stresses on the buckling behavior of arch sections. This first step is the determination of the size and shape of the residual stress field in an arch box section after the welding operations connecting the steel plates. To do this, a very detailed finite element model was developed, modeling the stress and temperature variation in the arch cross-sections due to the welding.

This model allowed for the determination of a residual weld stress distribution which is valid for box sections with a high as well as a low height-to-thickness ratio and having considerable dimensions of the cross-section. In a following step, these results are implemented on a full scale finite element model of an entire bridge to study its influence on the buckling behavior. However, this influence is proven to be rather small.

\section{REFERENCES}

Brown, S. and Song, H. 199), Finite element simulation of welding of large structures, J. Eng. Ind., 114(4), 441-451.

De Strycker, M.(2004, Numerieke simulatie en experimentele verificatie van eigenspanningen in gelaste stalen profielen, Master's Thesis, Ghent University (in Dutch).

EN 1993-1-1 2005, Eurocode 3: Design of steel structures, CEN, Brussels.

EN 1993-1-2 1999, Eurocode 3: Design of steel structures - Part 1-2: General rules - Structural fire design, CEN, Brussels.

EN 1993-2 2005, Eurocode 3: Design of steel structures - Part 2: Steel Bridges, CEN, Brussels.

European Convention for Constructional Steelwork (ECCS) 1976, Manual on the stability of steel structures, Puteaux (Paris).

Ferwin, M.R., and Scott, D.A. 1999, Finite element model of pulsed laser welding, Weld. J., Welding research supplement, 15-22.

Gery, D., Long, H. and Maropoulos, P. 2005, Effects of welding speed, energy input and heat source distribution on temperature variations in butt joints welding, J. Mater. Process. Tech., 167, 393-401.

Goldak, J., Chakravarti, A. and Bibby, M. 1984, A new finite element model for welding heat sources, Metall. Mater. Trans. B, 15(2), 299-305.

Lindgren, L.-E. 2001a, Finite element modeling and simulation of welding part 1: Increased complexity, J. Therm. Stresses, 24, 195-231.

Lindgren, L.-E. 2001b, Finite element modeling and simulation of welding part 2: Improved material modeling, J. Therm. Stresses, 24, 141-192.

Mass, E. and Massonet, C. 1966, The Belgian contribution to the experimental work of the ECCS, AcierStahl-Steel, 9.

Palani, P.L. and Murugan, N. 2006, Development of mathematical models for prediction of weld bead geometry in cladding by flux cored arc welding, Int. J. Adv. Manuf. Tech., 30(7-8), 669-676.

Runnemalm, H., Näsströom, O. and Lindgren, L.-E. 1999, Simulation of multipass weldings of a thick plate. Int. J. Numer. Meth. Eng., 44, 1301-1316.

Outtier, A., De Backer, H. and Van Bogaert, Ph. 2006, Lateral Buckling of a steel tied arch, Proceedings of 10th East Asia Pacific Conference on Structural Engineering \& Construction, Bangkok, August.

Recknagel, Sprenger, Hönman and Schramek 1995, Le Recknagel, Manuel pratique du génie climatique, tome 1 : Données fondamentals, PYC Edition livres (in French).

Samcef 2002. Samcef User Manual, v10.1 edition, Samtech, 2002.

Tebedge, N. and Tall, L. 1973, Residual stresses in structural steel shapes - a summary of measured val- 
ues - Technical Report 16.4, Frits Engineering Laboratory, Lehigh University.

Wahab, M. A. and Painter, M. J. 1977, Numerical models of gas Metal arc welds using experimentally determined weld pool shapes as the representation of the welding heat source, Int. J. Pres. Ves. Pip., 73, 153-159. 